\title{
Bioprospecção de rizobactérias para o controle in vitro de Pyricularia grisea, tratamento de sementes e promoção de crescimento de plântulas de arroz
}

\author{
Renata Silva Canuto de Pinho * \\ Bruna Canabarro Pozzebon \\ Caroline Carvalho Aguirre Calvano \\ Rosana Taschetto Vey \\ Amanda dos Santos Hajar \\ Bianca Moraes Rodrigues \\ Ketlen Raisa Rey Rodrigues \\ Universidade Federal do Pampa, Campus Itaqui \\ Rua Luiz Joaquim de Sá Britto, s/n, CEP 97.650-000, Itaqui - RS, Brasil \\ * Autor para correspondência \\ renatapinho@unipampa.edu.br
}

Submetido em 01/03/2019

Aceito para publicação em 15/07/2019

\section{Resumo}

Objetivou-se, com esse estudo, isolar e selecionar rizobactérias autóctones de arroz, com potencial para o controle in vitro de Pyricularia grisea, para o controle de fungos veiculados por sementes e para a promoção de crescimento em plântulas de arroz. Para isso, foram isoladas 18 rizobactérias autóctones de arroz, as quais foram submetidas ao teste de antibiose in vitro, em que se avaliou o índice de velocidade de crescimento micelial e o percentual de inibição de crescimento micelial. No tratamento de sementes com rizobactérias, as sementes foram bacterizadas e, posteriormente, avaliou-se a qualidade sanitária (incidência de fungos), a qualidade fisiológica (vigor, germinação e índice de velocidade de germinação de sementes) e a promoção de crescimento das plântulas. No teste de antibiose, todos os isolados apresentaram potencial de antagonismo frente à P. grisea. Houve melhorias na qualidade sanitária das sementes de arroz. Contudo, os isolados não apresentaram efeito positivo sobre a qualidade fisiológica das sementes. Três isolados induziram os maiores incrementos de parte aérea e raiz de plântulas de arroz na promoção de crescimento. Assim, conclui-se que as rizobactérias testadas apresentaram potencial de controle in vitro de fungos, em especial a $P$. grisea, e também para promoção de crescimento de plântulas de arroz.

Palavras-chave: Controle biológico; Índice de velocidade de germinação; Oryza sativa; Promoção de crescimento 


\section{Abstract}

Bioprospecting rhizobacteria for the in vitro control of Pyricularia grisea, seed treatment and growth promotion of rice seedlings. The objective of this study was to isolate and select autochthonous rice rhizobacteria with the potential for the in vitro control of Pyricularia grisea, the control of fungi propagated by seeds, and the growth promotion of rice seedlings. Accordingly, 18 isolates of autochthonous rice rhizobacteria were obtained and submitted to an in vitro antibiosis test, in which mycelial growth rate and percent inhibition of mycelial growth were evaluated. In seed treatment with rhizobacteria, seeds were exposed to the bacteria, and health quality (fungi incidence), physiological quality (vigor, germination and rate of seed germination) and growth promotion of the seedlings were then evaluated. In the antibiosis test, all the isolates displayed potential for antagonism against $P$. grisea. There were improvements in the health quality of rice seeds. However, the isolates had no positive effect on the physiological quality of the seeds. Three isolates induced the greatest increases in shoots and roots of rice seedlings in growth promotion. Thus, we conclude that the rhizobacteria tested have the potential to control fungi in vitro, especially P. grisea, and to promote the growth of rice seedlings as well.

Key words: Biological control; Germination speed index; Oryza sativa; Promotion of growth

\section{Introdução}

O arroz (Oryza sativa L.) é o segundo cereal mais cultivado em nível mundial, com área de plantio aproximada de 161 milhões de hectares (SOSBAI, 2018). No entanto, doenças causadas por fitopatógenos de etiologia fúngica são os principais fatores limitantes para o desenvolvimento e aumento da produção da cultura. Brusone (Pyricularia grisea), mancha parda (Bipolaris oryzae) e manchas dos grãos (Phoma sorghina, Bipolaris oryzae, Curvularia lunata, Nigroppora oryzae, Alternaria sp., Fusarium sp.) são exemplos de doenças veiculadas por sementes, que, quando não manejadas adequadamente, podem causar graves perdas de produtividade à cultura.

No caso da brusone do arroz, o fungo afeta diretamente a produção e qualidade dos grãos, sendo manifestada no campo, normalmente de forma epidêmica (NUNES; MARTINS, 2017). A doença possui alto potencial destrutivo, fazendo com que lavouras de arroz que apresentam severidade acima de $30 \%$ sejam abandonadas, devido aos danos econômicos causados (LUCAS et al., 2009). Com relação à mancha parda, a doença causa perdas tanto no rendimento quanto na qualidade dos grãos produzidos, podendo chegar a prejuízos de até 90\% no rendimento (PRABHU et al., 2006; CELMER et al., 2007; SUNDER, et al., 2014). Já a mancha dos grãos, causada por um complexo de espécies fúngicas distintas, pode surgir desde a fase de emissão das panículas até o amadurecimento dos grãos e tem ganhando importância fitopatológica devido aos prejuízos causados nas lavouras, com reduções de até $22 \%$ no número de grãos cheios por panícula (PRABHU et al., 2006; SANTOS et al., 2011).

Dessa forma, a qualidade sanitária das sementes é um dos aspectos que merece maior atenção nos sistemas produtivos e comércio agrícola, devido aos reflexos negativos que a associação de patógenos com sementes pode gerar (BARROCAS; MACHADO, 2010). Além disso, estabelecer padrões sanitários para os lotes de sementes está diretamente relacionado à qualidade da implantação da lavoura no campo, evitando a introdução de um novo patógeno em uma determinada área de cultivo e garantindo o máximo potencial produtivo da cultura.

Normalmente, o controle dessas doenças é feito mediante o tratamento de sementes ou via aplicação foliar de fungicidas. Contudo, apesar de eficaz, o controle químico aumenta os custos de produção e seus resíduos podem se acumular e contaminar o ambiente, além de aumentar a pressão de seleção, permitindo o surgimento de populações de patógenos resistentes aos princípios ativos comumente utilizados (CELMER et al., 2007; MOURA et al., 2014).

Nesse contexto, o controle biológico através do uso de microrganismos benéficos, com potencial para redução e/ou controle de fitopatógenos, pode ser uma alternativa a mais no manejo dos patógenos supracitados. As rizobactérias constituem um grupo 
de microrganismos que pode ser utilizado no controle biológico de doenças de plantas. Essas bactérias que colonizam saprofiticamente a rizosfera de plantas costumam se destacar como antagonistas de inúmeros fitopatógenos de solo, sendo capazes de proporcionar promoção de crescimento em diversas espécies de plantas e ativar mecanismos latentes na planta para indução de resistência sistêmica (MARCUZZO, 2010).

Com isso, objetivou-se com esse estudo, isolar e selecionar rizobactérias autóctones de arroz, com potencial para o controle in vitro de $P$. grisea, para o controle de fungos veiculados por sementes e para a promoção de crescimento em plântulas de arroz.

\section{Material e Métodos}

Os experimentos foram conduzidos no Laboratório de Fitopatologia e Microbiologia do Solo da Universidade Federal do Pampa (UNIPAMPA/Campus Itaqui), Rio Grande do Sul, Brasil.

\section{Isolamento e caracterização das rizobactérias}

As rizobactérias foram isoladas de raízes com solo de plantas de arroz aparentemente sadias, coletadas em seis pontos diferentes, nas cidades de Itaqui/ RS e Maçambará/RS. A metodologia utilizada para isolamento das rizobactérias foi a mesma proposta por Oostendorp e Sikora (1989), com adaptações. Para isso, descartou-se a parte aérea das plantas coletadas, e as raízes foram ligeiramente separadas do solo e cortadas em fragmentos de aproximadamente $0,5 \mathrm{~cm}$.

Posteriormente, foram pesados $10 \mathrm{~g}$ de cada amostra contendo raízes e solo, e cada amostra foi acondicionada em erlenmeyer com $100 \mathrm{~mL}$ de solução salina de $\mathrm{NaCl}$ a $0,1 \mathrm{~g} / \mathrm{mol}$. As amostras foram agitadas por 30 minutos em agitador orbital para liberação das bactérias. Em seguida, realizou-se uma diluição em série de cada amostra em solução salina de $\mathrm{NaCl}$ 0,1 g/ mol, com fator de diluição de 1:10 até $10^{-4}$. Alíquotas de $0,1 \mathrm{~mL}$ foram colocadas em placas de Petri, contendo meio de cultura 523 de Kado e Heskett (1970), e incubadas em câmara de crescimento tipo BOD a $28^{\circ} \mathrm{C}$, durante 24 h, para crescimento das colônias de rizobactérias. Transcorrido o período de incubação, as colônias bacterianas que apresentaram forma e coloração diferentes foram repicadas para tubos de ensaio contendo meio de cultura 523 inclinado, para manutenção e uso nos testes realizados nesse estudo.

Os isolados foram caracterizados morfologicamente, por meio da observação da colônia, observando-se coloração, alteração da cor do meio, forma da colônia e das bordas, superfície (lisa e rugosa) e brilho (brilhante, opaca, translúcida) (ZARPELON, 2007). Além disso, foi realizado também o teste de Gram, mediante a solubilidade em Hidróxido de Potássio 3\% $(\mathrm{KOH})$ (RYU, 1938).

O isolado de Pyricularia grisea foi cedido pelo Instituto Rio-Grandense de Arroz (IRGA - Unidade Cachoeirinha/RS).

\section{Potencial de antagonismo in vitro à Pyricularia grisea}

Os isolados rizobacterianos obtidos foram testados quanto ao potencial de antagonismo in vitro contra $P$. grisea. $\mathrm{O}$ teste de antibiose foi realizado de acordo com a metodologia proposta por Filippi et al. (2011).

Nessa metodologia, inicialmente, realizou-se a transferência de um disco de $0,5 \mathrm{~cm}$ de diâmetro com as estruturas vegetativas do patógeno, para o centro de placas de Petri, contendo meio de cultura BDA.

Posteriormente, cada isolado rizobacteriano foi repicado nos quatro extremos da placa de Petri, de maneira a formar um quadrado no entorno do patógeno fúngico, que foi repicado no centro da placa. A seguir, as placas, contendo os isolados bacterianos e o patógeno, foram incubadas em câmara de crescimento tipo BOD, a $25^{\circ} \mathrm{C}$ e fotoperíodo de $12 \mathrm{~h}$. Como tratamento controle, utilizou-se placas de Petri contendo apenas o disco de micélio de $P$. grisea no centro.

Foram avaliados o índice de velocidade de crescimento micelial (IVCM) e o percentual de crescimento micelial de $P$. grisea. Para isso, o diâmetro da colônia de $P$. grisea foi mensurado a cada 24 h, nos sentidos vertical e horizontal da placa de Petri, sendo 
a última avaliação realizada quando o patógeno no tratamento controle cresceu em toda a placa (FILIPPI et al., 2011).

O IVCM foi calculado através da fórmula $\mathrm{IVCM}=\sum(\mathrm{D}-\mathrm{Da}) / \mathrm{N}$, onde IVCM = índice de velocidade de crescimento micelial; $\mathrm{D}=$ diâmetro médio atual da colônia; $\mathrm{Da}=$ diâmetro médio da colônia do dia anterior; $\mathrm{N}$ = número de dias após a inoculação (MAIA et al., 2011). Já o percentual de inibição de crescimento micelial foi calculado pela fórmula $\%$ inibição $=100-$ (CM x 100/T); $\mathrm{CM}=$ diâmetro da colônia; $\mathrm{T}=$ diâmetro da colônia da testemunha.

O delineamento experimental foi inteiramente casualizado, com quatro repetições para cada isolado bacteriano. Os dados foram analisados estatisticamente no software SISVAR, versão 5.6 (FERREIRA, 2011), em que as médias foram submetidas à análise de variância e, quando significativas, agrupadas pelo teste de Scott$\operatorname{Knott}(P \leq 0,05)$.

\section{Bacterização das sementes de arroz}

Para a bacterização das sementes de arroz da cultivar PUITÁ INTA-CL, foram utilizadas culturas bacterianas com $24 \mathrm{~h}$ de crescimento no meio 523, postas em suspensão. Para o preparo dessas suspensões, adicionou-se solução salina $0,1 \mathrm{~g} / \mathrm{mol}$ às colônias, sendo estas raspadas com alça de Drigalski até a obtenção de suspensões homogêneas de células bacterianas, as quais foram ajustadas em espectrofotômetro para $\mathrm{OD}_{540}=0,5$

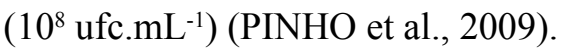

Posteriormente, as sementes foram acondicionadas em erlenmeyers e permaneceram imersas nas respectivas suspensões bacterianas durante 30 minutos, sob agitação constante em Shaker a $100 \mathrm{rpm}$ a $25^{\circ} \mathrm{C}$. Como controle negativo, foram utilizadas sementes imersas em solução salina $0,1 \mathrm{~g} / \mathrm{mol}$, apenas. Após a bacterização, as sementes foram dispostas em caixas gerbox, sob duas folhas de papel próprio para germinação (papel Germitest) esterilizados, previamente umedecidos com água destilada e esterilizada em quantidade equivalente a 2,5 vezes o peso do papel. Por fim, as caixas foram incubadas em câmara de crescimento tipo BOD, a $25^{\circ} \mathrm{C}$ e fotoperíodo de $12 \mathrm{~h}$, durante sete dias.
Incidência de fungos nas sementes e identificação

Ao final do sétimo dia de incubação, realizou-se a avaliação da incidência dos principais patógenos fúngicos de sementes de arroz (P. grisea, Phoma sp., e Bipolaris oryzae), por meio da observação individual de cada semente em microscópio estereoscópico e identificação dos patógenos por chave dicotômica (BARNETT; HUNTER, 1986).

Os ensaios foram conduzidos em delineamento experimental inteiramente casualizado (DIC), em que cada tratamento foi composto por 100 sementes e quatro repetições. Os resultados foram expressos em percentual de ocorrência dos fungos em cada amostra de sementes tratadas com rizobactérias (BRASIL, 2009).

\section{Teste padrão de germinação, índice de velocidade de germinação de sementes e crescimento de plântulas}

Concomitantemente, foram conduzidos testes de vigor (primeira contagem da germinação), germinação (segunda contagem da germinação) e tamanho de plântulas de arroz, visando caracterizar o lote de sementes, bem como avaliar o potencial dos isolados bacterianos em melhorar a qualidade fisiológica das sementes e estimular o crescimento de plântulas.

A metodologia utilizada seguiu os padrões recomendados pelas Regras de Análises de Sementes (RAS) (BRASIL, 2009). No teste de germinação e índice de velocidade de germinação (IVG), foram utilizadas quatro repetições compostas por 25 sementes cada, distribuídas em papel Germitest umedecido com água destilada esterilizada, na proporção de 2,5 vezes o peso do papel, acondicionados em caixas gerbox.

A avaliação do vigor de sementes constituiu-se do registro de plântulas normais verificadas na primeira contagem do teste de germinação, realizada aos cinco dias após a semeadura em papel Germitest, conforme os padrões da RAS (BRASIL, 2009). Aos 14 dias, foi avaliado o total de plântulas normais, seguindo os padrões estabelecidos pela RAS. Os percentuais de plântulas normais de cada repetição foram computados 
para avaliação da germinação. Em paralelo ao teste de germinação, analisou-se também o IVG, no qual as sementes foram avaliadas diariamente até o $14^{\circ}$ dia, e posteriormente foi feito o cálculo do IVG de acordo com a fórmula de Maguire (1962):

$$
\mathrm{IVG}=(\mathrm{G} 1 / \mathrm{N} 1)+(\mathrm{G} 2 / \mathrm{N} 2)+(\mathrm{G} 3 / \mathrm{N} 3)+\ldots+(\mathrm{Gn} / \mathrm{Nn})
$$

onde:

IVG = índice de velocidade de germinação;

G1, G2, G3, ..., Gn = número de plântulas computadas na primeira, segunda, terceira e última contagem;

$\mathrm{N} 1, \mathrm{~N} 2, \mathrm{~N} 3, \ldots, \mathrm{Nn}=$ número de dias da semeadura na primeira, segunda, terceira e última contagem.

Além disso, avaliou-se o crescimento de plântulas de arroz, mediante mensuração do comprimento da raiz e parte aérea, aos 14 dias após a semeadura em papel Germitest.

O delineamento experimental foi inteiramente casualizado e os dados foram expressos em porcentagem. Os resultados obtidos foram analisados estatisticamente no software SISVAR, versão 5.6 (FERREIRA, 2011), sendo as médias submetidas à análise de variância e, quando significativas, agrupadas pelo teste de ScottKnott $(p \leq 0,05)$.

\section{Resultados}

Foram isoladas 18 bactérias da rizosfera das plantas de arroz provenientes dos municípios de Itaqui e Maçambará/RS (Tabela 1). De maneira geral, os isolados apresentaram colônias de coloração creme claro, brilho opaco e nenhuma alteração da cor do meio de cultura 523. A superficie variou entre lisa e rugosa, os formatos das colônias e das bordas variaram entre irregulares e circulares. $\mathrm{O}$ teste de solubilidade em $\mathrm{KOH}$ a $3 \%$ mostrou que não houve aumento da viscosidade para nenhum dos isolados testados, demonstrando dessa forma que as rizobactérias são Gram-positivas, podendo ser identificadas, em nível de gênero, como Bacillus spp., baseando-se nesse conjunto de características (ZARPELON, 2007).

Todos os isolados testados apresentaram inibição ao crescimento in vitro de Pyricularia grisea em maior ou menor percentual (Tabela 1). Destes, 11\% do total (BAC24 e BAC30) reduziram o IVCM e $72 \%$ (BAC35, 18, 37, 39, 33, 25, 28, 8, 27, 23, 22, 29,32 , respectivamente) aumentaram o percentual de inibição micelial do patógeno acima de $50 \%$, com inibição máxima de $71,53 \%$ do crescimento micelial de $P$. grisea pelo isolado BAC 35 . Além disso, os cinco

FIGURA 1: Antagonismo in vitro do isolado rizobacteriano BAC24 a Pyricularia grisea, comparado ao tratamento controle.

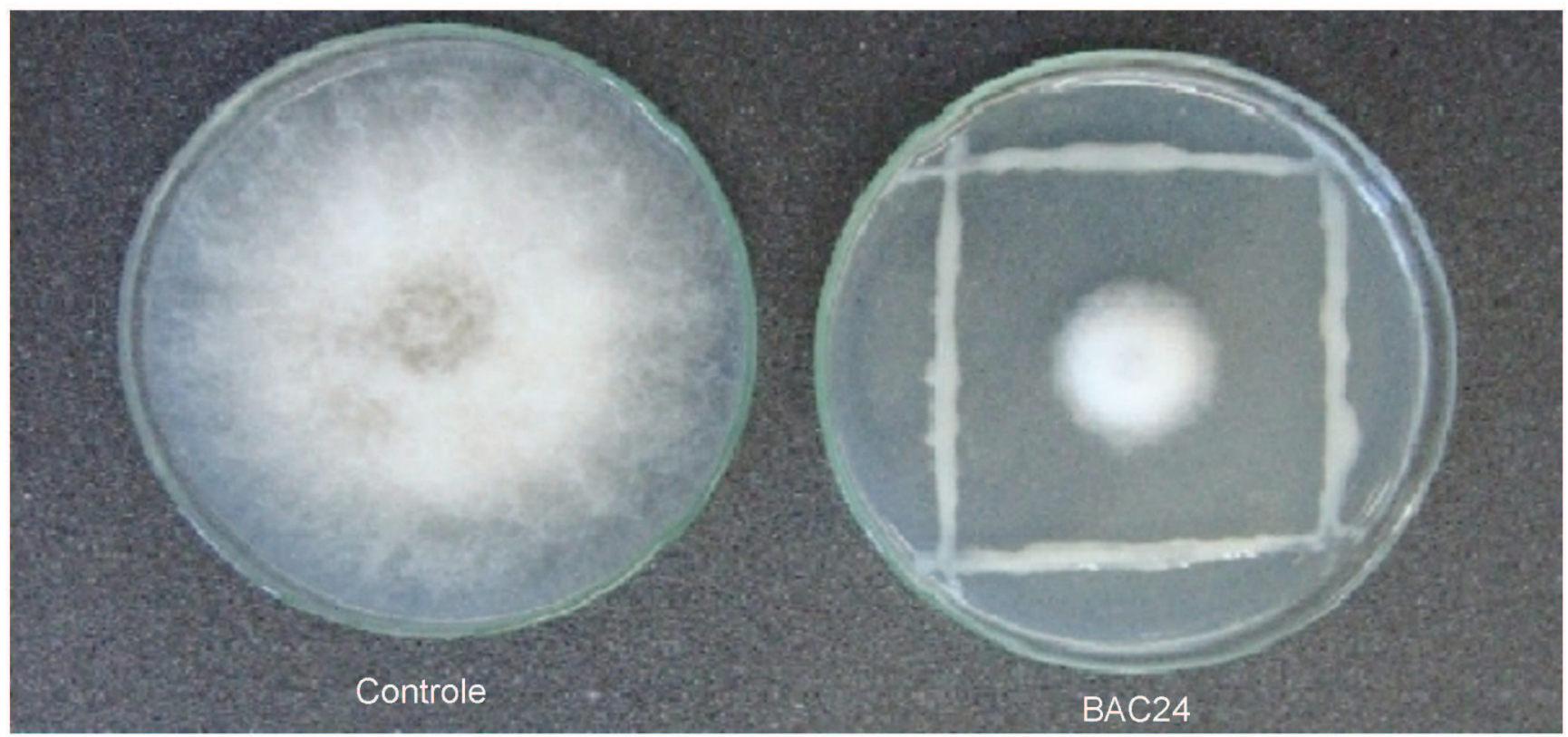


isolados restantes (28\% do total) (BAC 24, 06, 38, 30 e 31, respectivamente) também inibiram o crescimento micelial entre 35,69-45,83\%. Já os isolados BAC24 e BAC30 apresentaram os menores índices de velocidade de crescimento micelial, quando comparados com o tratamento controle (Tabela 1; Figura 1).

Em relação ao teste de sanidade, todos os 18 isolados rizobacterianos testados reduziram a incidência de patógenos fúngicos nas sementes de arroz. $\mathrm{O}$ isolado BAC 27 foi o mais eficaz, sendo que as sementes tratadas com esse isolado obtiveram uma incidência de fungos fitopatogênicos de $11 \%$ (Tabela 1).
Além disso, quando se avaliou especificamente os fungos mais importantes na sanidade de sementes de arroz (BRASIL, 2009), verificou-se que todos os isolados reduziram a incidência de $P$. grisea e Phoma sp. quando comparados com o controle (sementes não tratadas com rizobactérias) e 12 isolados (BAC06, $08,24,25,29,30,31,32,33,35,38$ e 39$)$ reduziram a incidência de $B$. oryzae, quando comparados com o tratamento controle (Tabela 2). O isolado BAC 33 foi o mais eficaz na redução da incidência dos três patógenos avaliados (Tabela 2).

TABELA 1: Efeito de rizobactérias obtidas em diferentes municípios do Rio Grande do Sul, no índice de velocidade de crescimento micelial (IVCM), porcentagem de inibição de crescimento micelial de P. grisea, in vitro, e na incidência de fungos em sementes de arroz.

\begin{tabular}{ccccc}
\hline Tratamento & $\begin{array}{c}\text { Procedência do } \\
\text { isolado }\end{array}$ & IVCM & $\begin{array}{c}\text { \% de inibição de crescimento } \\
\text { micelial }\end{array}$ & Incidência (\%) \\
\hline BAC24 & Itaqui/RS & $0,87 \mathrm{a}^{*}$ & $35,69 \mathrm{~b}$ & $42,00 \mathrm{c}^{*}$ \\
BAC30 & Itaqui/RS & $0,89 \mathrm{a}$ & $45,14 \mathrm{~b}$ & $61,00 \mathrm{e}$ \\
BAC29 & Itaqui/RS & $1,06 \mathrm{~b}$ & $52,92 \mathrm{a}$ & $49,00 \mathrm{~d}$ \\
BAC22 & Itaqui/RS & $1,12 \mathrm{~b}$ & $54,17 \mathrm{a}$ & $40,00 \mathrm{c}$ \\
BAC38 & Itaqui/RS & $1,13 \mathrm{~b}$ & $43.89 \mathrm{~b}$ & $35,00 \mathrm{~b}$ \\
BAC27 & Itaqui/RS & $1,17 \mathrm{c}$ & $56,39 \mathrm{a}$ & $11,00 \mathrm{a}$ \\
BAC31 & Itaqui/RS & $1,23 \mathrm{c}$ & $45,83 \mathrm{~b}$ & $51,00 \mathrm{~d}$ \\
BAC06 & Maçambará/RS & $1,30 \mathrm{~d}$ & $42,78 \mathrm{~b}$ & $50,00 \mathrm{~d}$ \\
BAC32 & Itaqui/RS & $1,34 \mathrm{~d}$ & $51,95 \mathrm{a}$ & $49,00 \mathrm{~d}$ \\
BAC37 & Itaqui/RS & $1,34 \mathrm{~d}$ & $60,70 \mathrm{a}$ & $47,00 \mathrm{c}$ \\
BAC39 & Itaqui/RS & $1,38 \mathrm{e}$ & $60,28 \mathrm{a}$ & $28,00 \mathrm{~b}$ \\
BAC18 & Itaqui/RS & $1,42 \mathrm{e}$ & $67,22 \mathrm{a}$ & $29,00 \mathrm{~b}$ \\
BAC25 & Itaqui/RS & $1,44 \mathrm{e}$ & $58,19 \mathrm{a}$ & $38,00 \mathrm{c}$ \\
BAC08 & Maçambará/RS & $1,53 \mathrm{f}$ & $57,36 \mathrm{a}$ & $40,00 \mathrm{c}$ \\
BAC23 & Itaqui/RS & $1,58 \mathrm{f}$ & $56,11 \mathrm{a}$ & $45,00 \mathrm{c}$ \\
BAC28 & Itaqui/RS & $1,64 \mathrm{~g}$ & $57,50 \mathrm{a}$ & $52,00 \mathrm{~d}$ \\
BAC33 & Itaqui/RS & $1,66 \mathrm{~g}$ & $59,31 \mathrm{a}$ & $49,00 \mathrm{~d}$ \\
BAC35 & Itaqui/RS & $1,97 \mathrm{~h}$ & $71,53 \mathrm{a}$ & $61,00 \mathrm{e}$ \\
Controle & - & $2,77 \mathrm{i}$ & $0,0 \mathrm{c}$ & $97,00 \mathrm{f}$ \\
\hline CV $(\%)=$ & 4,14 & 14,28 & 12,20 \\
\hline
\end{tabular}

* Médias seguidas pela mesma letra na coluna pertencem ao mesmo grupo pelo teste de $\operatorname{Scott-Knott~}(P \leq 0,05)$. 
TABELA 2: Efeito do tratamento de sementes de arroz com rizobactérias na incidência de P. grisea, Phoma sp. e Bipolaris oryzae.

\begin{tabular}{c|c|c|c}
\hline \multicolumn{2}{|c}{ Fungos (\%) } \\
\hline Tratamento & Pyricularia grisea & Phoma sp. & Bipolaris oryzae \\
\hline BAC06 & $4,00 \mathrm{~b}^{* *}$ & $0,00 \mathrm{a}$ & $0,00 \mathrm{a}^{*}$ \\
BAC08 & $0,00 \mathrm{a}$ & $33,00 \mathrm{e}$ & $0,0 \mathrm{a}$ \\
BAC18 & $0,00 \mathrm{a}$ & $19,00 \mathrm{c}$ & $8,00 \mathrm{c}$ \\
BAC22 & $0,00 \mathrm{a}$ & $33,00 \mathrm{e}$ & $8,00 \mathrm{c}$ \\
BAC23 & $0,00 \mathrm{a}$ & $8,00 \mathrm{~b}$ & $6,00 \mathrm{~b}$ \\
BAC24 & $5,00 \mathrm{~b}$ & $17,00 \mathrm{c}$ & $0,00 \mathrm{a}$ \\
BAC25 & $0,00 \mathrm{a}$ & $23,00 \mathrm{~d}$ & $0,00 \mathrm{a}$ \\
BAC27 & $11,00 \mathrm{c}$ & $31,00 \mathrm{e}$ & $33,00 \mathrm{~d}$ \\
BAC28 & $0,00 \mathrm{a}$ & $12,00 \mathrm{c}$ & $9,00 \mathrm{c}$ \\
BAC29 & $6,00 \mathrm{~b}$ & $5,00 \mathrm{~b}$ & $0,00 \mathrm{a}$ \\
BAC30 & $0,00 \mathrm{a}$ & $15,00 \mathrm{c}$ & $0,00 \mathrm{a}$ \\
BAC31 & $0,00 \mathrm{a}$ & $33,00 \mathrm{e}$ & $0,00 \mathrm{a}$ \\
BAC32 & $0,00 \mathrm{a}$ & $16,00 \mathrm{c}$ & $1,00 \mathrm{a}$ \\
BAC33 & $0,00 \mathrm{a}$ & $2,00 \mathrm{a}$ & $0,00 \mathrm{a}$ \\
BAC35 & $9,00 \mathrm{c}$ & $11,00 \mathrm{c}$ & $0,00 \mathrm{a}$ \\
BAC37 & $0,00 \mathrm{a}$ & $22,00 \mathrm{~d}$ & $9,00 \mathrm{c}$ \\
BAC38 & $10,00 \mathrm{c}$ & $29,00 \mathrm{e}$ & $0,00 \mathrm{a}$ \\
BAC39 & $11,00 \mathrm{c}$ & $29,00 \mathrm{e}$ & $0,00 \mathrm{a}$ \\
\hline Controle & $18,50 \mathrm{~d}$ & $41,00 \mathrm{f}$ & $7,00 \mathrm{~b}$ \\
\hline CV\% & 34,53 & 24,23 & 41,23 \\
\hline
\end{tabular}

* Médias seguidas pela mesma letra na coluna pertencem ao mesmo grupo pelo teste de Scott-Knott $(P \leq 0,05)$. ** Os dados de Pyricularia grisea foram transformados em $\sqrt{\mathrm{x}+0,5}$.

Todavia, apesar de não diferir do controle, os tratamentos BAC08, 18, 22, 23, 24, 25, 30, 31, 32, 33 e 37 tiveram efeito positivo sobre o índice de velocidade de germinação (IVG), diferindo dos tratamentos BAC38, $39,27,29,06,35$ e 25 , que apresentaram os menores IVG. O mesmo ocorreu na avaliação da porcentagem de vigor e germinação, em que os isolados BAC06, $08,18,22,23,24,25,27,28,30,31,32,33,35$ e 37 , apesar de não diferirem do tratamento controle, diferiram dos isolados BAC30, 38 e 39, os quais apresentaram as menores porcentagens de vigor e germinação de sementes de arroz (Tabela 3). 
TABELA 3: Efeito de rizobactérias na qualidade fisiológica de sementes de arroz.

\begin{tabular}{c|c|c|c}
\hline Tratamento & IVG & Vigor $-\mathbf{5}$ dias & Germinação $-\mathbf{1 4}$ dias \\
\hline BAC06 & $3,29 \mathrm{~b}^{*}$ & $92,00 \mathrm{a}^{*}$ & $95,00 \mathrm{a}^{*}$ \\
BAC08 & $4,34 \mathrm{a}$ & $90,00 \mathrm{a}$ & $91,00 \mathrm{a}$ \\
BAC18 & $5,57 \mathrm{a}$ & $96,00 \mathrm{a}$ & $97,00 \mathrm{a}$ \\
BAC22 & $5,01 \mathrm{a}$ & $75,00 \mathrm{a}$ & $96,00 \mathrm{a}$ \\
BAC23 & $5,67 \mathrm{a}$ & $90,00 \mathrm{a}$ & $91,00 \mathrm{a}$ \\
BAC24 & $4,32 \mathrm{a}$ & $76,00 \mathrm{a}$ & $92,00 \mathrm{a}$ \\
BAC25 & $4,05 \mathrm{a}$ & $88,00 \mathrm{a}$ & $96,00 \mathrm{a}$ \\
BAC27 & $2,53 \mathrm{~b}$ & $91,00 \mathrm{a}$ & $94,00 \mathrm{a}$ \\
BAC28 & $3,61 \mathrm{~b}$ & $92,00 \mathrm{a}$ & $93,00 \mathrm{a}$ \\
BAC29 & $2,66 \mathrm{~b}$ & $40,00 \mathrm{~b}$ & $54,00 \mathrm{~b}$ \\
BAC30 & $4,17 \mathrm{a}$ & $89,00 \mathrm{a}$ & $95,00 \mathrm{a}$ \\
BAC31 & $4,43 \mathrm{a}$ & $88,00 \mathrm{a}$ & $89,00 \mathrm{a}$ \\
BAC32 & $4,50 \mathrm{a}$ & $95,00 \mathrm{a}$ & $96,00 \mathrm{a}$ \\
BAC33 & $5,14 \mathrm{a}$ & $94,00 \mathrm{a}$ & $98,00 \mathrm{a}$ \\
BAC35 & $3,55 \mathrm{~b}$ & $88,00 \mathrm{a}$ & $90,00 \mathrm{a}$ \\
BAC37 & $5,81 \mathrm{a}$ & $96,00 \mathrm{a}$ & $96,00 \mathrm{a}$ \\
BAC38 & $2,02 \mathrm{~b}$ & $0,000 \mathrm{c}$ & $57,00 \mathrm{~b}$ \\
BAC39 & $2,10 \mathrm{~b}$ & $43,00 \mathrm{~b}$ & $71,00 \mathrm{~b}$ \\
Controle & $5,98 \mathrm{a}$ & $81,50 \mathrm{a}$ & $97,00 \mathrm{a}$ \\
\hline CV\% & 33,89 & 21,98 & 12,73 \\
\hline
\end{tabular}

* Médias seguidas pela mesma letra na coluna pertencem ao mesmo grupo pelo teste de Scott-Knott $(P \leq 0,05)$.

Já com relação à promoção de crescimento de plântulas aos 14 dias após a inoculação das sementes, observou-se que 11 isolados (BAC06, 08, $18,24,25,27,28,32,33,35$ e 37 ) foram eficazes no desenvolvimento da raiz de plântulas de arroz e 12 isolados (BAC06, 08, 18, 22, 24, 25, 27, 28, 32, 33, 35 e 37) foram promissores no aumento do comprimento da parte aérea (Tabela 4). Os isolados BAC06, BAC08, BAC28 foram os mais eficazes para os dois parâmetros avaliados (Tabela 4). 
TABELA 4: Comprimento de raiz e parte aérea de plântulas de arroz após tratamento com rizobactérias.

\begin{tabular}{|c|c|c|}
\hline Tratamento & Comprimento Raiz (cm) & Comprimento parte aérea $(\mathrm{cm})$ \\
\hline BAC06 & $4,25 \mathrm{a}^{*}$ & $3,67 \mathrm{a}^{*}$ \\
\hline $\mathrm{BAC} 08$ & $4,46 \mathrm{a}$ & $3,96 \mathrm{a}$ \\
\hline BAC18 & $3,84 \mathrm{~b}$ & $4,05 \mathrm{a}$ \\
\hline $\mathrm{BAC} 22$ & $2,80 \mathrm{c}$ & $2,86 \mathrm{a}$ \\
\hline $\mathrm{BAC} 23$ & $0,87 \mathrm{~d}$ & $0,59 \mathrm{c}$ \\
\hline BAC24 & $3,66 \mathrm{~b}$ & $3,77 \mathrm{a}$ \\
\hline $\mathrm{BAC} 25$ & $3,52 \mathrm{~b}$ & $4,18 \mathrm{a}$ \\
\hline $\mathrm{BAC} 27$ & $3,18 \mathrm{~b}$ & $3,00 \mathrm{a}$ \\
\hline $\mathrm{BAC} 28$ & $4,51 \mathrm{a}$ & $4,14 \mathrm{a}$ \\
\hline BAC29 & $2,22 \mathrm{c}$ & $1,50 \mathrm{~b}$ \\
\hline BAC30 & $2,69 \mathrm{c}$ & $2,35 \mathrm{~b}$ \\
\hline BAC31 & $2,54 \mathrm{c}$ & $1,97 \mathrm{~b}$ \\
\hline $\mathrm{BAC} 32$ & $3,37 \mathrm{~b}$ & $3,37 \mathrm{a}$ \\
\hline BAC33 & $3,69 \mathrm{~b}$ & $4,06 \mathrm{a}$ \\
\hline $\mathrm{BAC} 35$ & $3,18 \mathrm{~b}$ & $3,36 \mathrm{a}$ \\
\hline BAC37 & $3,37 \mathrm{~b}$ & $3,10 \mathrm{a}$ \\
\hline $\mathrm{BAC} 38$ & $1,35 \mathrm{~d}$ & $0,53 \mathrm{c}$ \\
\hline BAC39 & $1,88 \mathrm{c}$ & $1,63 \mathrm{~b}$ \\
\hline Controle & $2,82 \mathrm{c}$ & $1,91 \mathrm{~b}$ \\
\hline CV \% & 22,58 & 28,32 \\
\hline
\end{tabular}

* Médias seguidas pela mesma letra na coluna pertencem ao mesmo grupo pelo teste de Scott-Knott $(P \leq 0,05)$.

\section{Discussão}

O controle biológico exercido por bactérias benéficas sobre patógenos ocorre por diferentes mecanismos, tais como a síntese de compostos voláteis, metabólitos secundários, ácido cianídrico (HCN) e antibióticos, de forma isolada ou em conjunto. Esses mecanismos de biocontrole das bactérias benéficas têm demonstrado eficiência em inibir o crescimento de fungos in vitro, podendo em muitas situações explicar, pelo menos em parte, o controle biológico de doenças de plantas promovido por procariotos (LIMA et al., 2014).

Neste estudo, 18 isolados de rizobactérias foram testados na inibição in vitro do crescimento micelial de Pyricularia grisea, e todos apresentaram atividade antagônica ao patógeno desafiante. Corroborando os resultados obtidos nesse trabalho, Chaibub et al. (2011) verificaram que todos os 30 isolados de rizobactérias confrontados in vitro contra $P$. grisea reduziram o crescimento micelial do patógeno. Nejad et al. (2014) obtiveram cinco isolados bacterianos com potencial de antagonismo in vitro frente ao crescimento micelial de Bipolaris oryzae. Da mesma forma, Filippi et al. (2011) avaliaram a supressão de $P$. grisea in vitro e observaram que todos os isolados testados reduziram o crescimento do patógeno com valores de $67 \%$ a $85 \%$, confirmando, dessa forma, a atividade antagônica desses microrganismos, quando confrontados diretamente com o patógeno desafiante. Lipopeptídeos das famílias da surfactina, iturina, lichenicina e fengicina, sintetizados por espécies de Bacillus, apresentam efeito inibitório sobre diversos patógenos (AL-BAHRY et al., 2013; SOUZA et al., 2014; LIU et al., 2015). Apesar de não terem sido caracterizadas neste estudo, essas moléculas podem estar envolvidas no antagonismo in vitro contra P. grisea. 
Com relação à qualidade sanitária das sementes, verificou-se que todos os isolados rizobacterianos reduziram a incidência de fungos veiculados pelas sementes de arroz. Bezerra et al. (2013) avaliaram a incidência e o controle de fitopatógenos mediante microbiolização de sementes de soja com isolados bacterianos de Bacillus licheniformis e Bacillus pumilus, os quais reduziram a incidência de patógenos em $99,83 \%$ e $99,22 \%$, respectivamente. Notadamente, os isolados rizobacterianos deste estudo podem estar atuando através da competição direta por nutrientes, síntese de substâncias antimicrobianas, secreção de enzimas, síntese de compostos voláteis ou indução de resistência sistêmica, reduzindo, dessa forma, a incidência de fitopatógenos nas sementes de arroz.

Além de reduzir a incidência geral de fungos, o tratamento de sementes de arroz com rizobactérias proporcionou o controle dos principais patógenos transmitidos por sementes (P. grisea, Phoma sp. e $B$. oryzae). Anacker et al. (2010) verificaram que alguns isolados de bactérias benéficas reduziram a incidência de mancha parda (B. oryzae) em plantas de arroz, sob condições de casa de vegetação após o tratamento de sementes de arroz com as bactérias. Souza Júnior et al. (2017), ao tratar sementes de arroz com rizobactérias, obtiveram controle médio da brusone de $45 \%$ quando comparados ao tratamento controle.

O tratamento de sementes com rizobactérias também pode propiciar um melhor desenvolvimento da planta. Filippi et al. (2011), ao tratar sementes de arroz com rizobactérias, encontraram 18 isolados capazes de estimular o crescimento de plantas e suprimir a incidência de brusone em até 95\%, nos estágios iniciais de desenvolvimento das plântulas. Isso ocorreu porque as rizobactérias desencadearam o fenômeno de resistência sistêmica induzida (IRS), gerado pelo aumento da atividade enzimática de proteínas relacionadas à patogênese (PRPs), tais como peroxidase (POX), $\beta$-1,3glucanase e quitinase (FILIPPI et al., 2011). Dessa forma, o tratamento de sementes com rizobactérias, além de melhorar a qualidade sanitária das sementes, pode desencadear o fenômeno de resistência sistêmica induzida, durante o desenvolvimento da cultura no campo.
Com relação ao teste de promoção de crescimento, os isolados BAC06, BAC08 e BAC28 foram os mais promissores no aumento do comprimento da raiz e da parte aérea das plântulas. Da mesma forma, Moura et al. (2014), observaram aumento no comprimento de raízes e da parte aérea de plantas de arroz tratadas com bactérias benéficas. Rodrigues et al. (2016), também verificaram a promoção de crescimento de plantas de cana-de-açúcar através do uso de bactérias benéficas.

Dessa forma, os resultados obtidos mostraram que todas as rizobactérias avaliadas no presente estudo são capazes de atuar como antagonistas a $P$. grisea, reduzindo em maior ou menor grau o crescimento micelial do patógeno in vitro. Além disso, todas as rizobactérias avaliadas no presente estudo foram capazes de reduzir a incidência de fungos nas sementes de arroz tratadas e alguns dos isolados avaliados foram eficazes na promoção de crescimento de plântulas. Os isolados mais promissores no presente trabalho serão posteriormente avaliados quanto ao potencial de incremento na qualidade fisiológica e sanitária de sementes de arroz submetidas a diferentes épocas de armazenamento. Com relação ao patógeno $P$. grisea, serão conduzidos experimentos adicionais em condições de casa de vegetação com o intuito de elucidar possíveis mecanismos de ação envolvidos no controle da brusone.

\section{Agradecimentos}

Os autores agradem à Universidade Federal do Pampa pela estrutura e financiamento do estudo, aos integrantes do Laboratório de Fitopatologia e Microbiologia do Solo e ao Grupo de Estudos em Fitopatologia, pelo auxílio na condução dos experimentos e ao senhor Benjamin F. Pozzebon, pelo auxílio na coleta das amostras.

\section{Referências}

AL-BAHRY, S. N.; AL-WAHAIBI, Y. M.; ELSHAFIE, A. E.; AL-BEMANI, A. S.; JOSHI, S. J.; AL-AKHMARI, H. S.; ALSULAIMANI, H. S. Biosurfactant production by Bacillus subtilis B20 using date molasses and its possible application in enhanced oil recovery. International Biodeterioration \& Biodegradation, Barking, v. 81, p. 141-146, 2013. 
ANACKER, L. F.; SCHAFER, J. T.; CORREA, B. O.; BENEDETI, P. R.; ANDRÉA B. M. Controle biológico da mancha parda em arroz irrigado pelo uso de rizobactérias isoladas e combinadas. In: CONGRESSO DE INICIAÇÃO CIENTÍFICA, ENCONTRO DE PÓS GRADUAÇÃO e MOSTRA CIENTÍFICA, XIX, XII, II, 2010, Pelotas. Resumos... Pelotas: UFPEL, 2010. Versão eletrônica.

BARNETT, H. L.; HUNTER, B.B. Illustrated genera of imperfect fungi. 4. ed. New York: Macmillan Publishing Company, 1986. $218 \mathrm{p}$.

BARROCAS, E. N.; MACHADO, J. C. Introdução a patologia de sementes e testes convencionais de sanidade de sementes para a detecção de fungos fitopatogênicos. Informativo ABRATES, Londrina, v. 20, n. 3, p. 74-77, 2010.

BEZERRA, G. A.; MACEDO, D. A.; NASCIMENTO, I. O.; SOUSA, T. P.; COSTA, N. B.; SOUSA, L. F. R. A. Uso de Bacillus spp. no controle de fitopatógenos em sementes de soja variedade BRS Valiosa RR. Agrossistemas, Belém, v. 5, n. 1, p. 68-73, 2013. BRASIL - MINISTÉRIO DA AGRICULTURA, PECUÁRIA E ABASTECIMENTO. Regras para análise de sementes. Brasília: Secretaria de Defesa Agropecuária, 2009. 395 p.

CElMer, A.; MADAlosso, M. G.; DEBORTOLI, M. P.; NAVARINI, L.; BALARDIN, R. S. Controle químico de doenças foliares na cultura do arroz irrigado. Pesquisa Agropecuária Brasileira, Brasília, v. 42, p. 901-904, 2007.

CHAIBUB, A. A.; SENA, A. P. A.; MAGALHÃES, M. S.; CORTES, M. V. C. B.; SILVA-LOBO, V. L.; FILIPPI, M. C. C.; ARAUJO, L. G. Antagonismo in vitro e in vivo entre Magnaporthe oryzae e bactérias do filoplano do arroz. In: CONGRESSO BRASILEIRO DE FITOPATOLOGIA, 44, 2011, Bento Gonçalves. Resumos... Bento Gonçalves: Sociedade Brasileira de Fitopatologia, 2011. Versão eletrônica.

FERREIRA, D. F. Sisvar: a computer statistical analysis system. Ciência e Agrotecnologia, Lavras, v. 35, p. 1039-1042, 2011.

FILIPPI, M. C. C.; SILVA, G. B.; SILVA-LOBO, V. L.; CORTES, M. V. C. B.; MORAES, A. J. G.; PRABHU, A. S. Leaf blast (Magnaporthe oryzae) suppression and growth promotion by rhizobacteria on aerobic rice in Brazil. Biological Control, Cambridge, v. 58, p. 160-166, 2011.

KADO, C. L.; HESKETT, M. G. Selective media for isolation of Agrobacterium, Corynebacterium, Erwinia, Pseudomonas and Xanthomonas. Phytopathology, East Lansing, v. 60, p. 969-976, 1970.

LIMA, O. D. R.; OLIVEIRA, L. J. M. G.; SILVA, M. S. B. S; RODRIGUES, A. A. C. Ação antifúngica in vitro de isolados de Bacillus ssp. sobre Fusarium oxysporum f. sp. lycopersici. Revista Caatinga, Mossoró, v. 27, n. 4, p. 57-64, 2014.

LIU, Q.; LIN, J.; WANG, W.; HUANGA, H.; LI, S. Production of surfactin isoforms by Bacillus subtilis BS-37 and its applicability to enhanced oil recovery under laboratory conditions. Biochemical Engineering Journal, Amsterdam, v. 93, p. 31-37, 2015.

LUCAS, J. A.; SOLANO, B. R.; MONTES, F.; OJEDA, J.; MEGIAS, M.; MANERO, F. J. G. Use of two PGPR strains in the integrated management of blast disease in rice (Oryza sativa) in Southern Spain. Field Crops Research, Weigang, v. 114, p. 404410, 2009.
MAGUIRE, J. D. Speed of germination-aid in selection and evaluation for seedling emergence and vigor. Crop Science, Madison, v. 2, n. 2, p. 176-177, 1962.

MAIA, F. G. M.; ARMESTO, C.; ZANCAN, W. L. A.; MAIA, J. B.; ABREU, M. S. de. Efeito da temperatura no crescimento micelial, produção e germinação de conídios de Colletotrichum spp. isolados de mangueira com sintomas de antracnose. Bioscience Journal, Uberlândia, v. 27, n. 2, p. 205-210, 2011.

MARCUZZO, L. L. Efeito de rizobactérias sobre o biocontrole e promoção de crescimento de plantas. Ágora: Revista de Divulgação Cientifica, Mafra, v. 17, n. 1, p. 1-11, 2010.

MOURA, A. B.; LUDWIG, J.; SANTOS, A. G.; SCHAFER, J. T.; SOARES, V. N.; CORRÊA, B. O. Biocontrol and seed transmission of Bipolaris oryzae and Gerlachia oryzae to rice seedlings. Journal of Seed Science, Londrina, v. 36, n. 4, p. 407-412, 2014.

NEJAD, M. S.; BONJAR, G. H. S.; DEHKAEI, F. P. Control of Bipolaris oryzae the causal agent of rice brown spot disease via soil Streptomyces sp. isolate G. International Journal of Advanced Biological and Biomedical Research, New Delhi, v. 2, p. 310-317, 2014.

NUNES, C. D. M.; MARTINS, J. F. da S. Eficiência de fungicidas no controle da brusone do arroz irrigado na safra 2015/2016. In: CONGRESSO BRASILEIRO DE ARROZ IRRIGADO, 10, 2017, Gramado. Resumos... Gramado: SOSBAI, 2017. Versão eletrônica.

OOSTENDORP, M.; SIKORA, R. A. Seed treatment with antagonistic rhizobacteria for the suppression of Heterodera schachtii early root infection of sugar beet. Revue de Nématologie, Paris, v. 1, n. 12, p. 77-83, 1989.

PINHO, R. S. C.; CAMPOS, V. P.; SOUZA, R. M.; SILVA, J. R. C.; OLIVEIRA, M. S.; PIMENTEL, G. C. S.; COSTA, S. A. S. Efeito de bactérias endofíticas no controle de Meloidogyne incognita e sua capacidade de colonização de raízes de tomateiro. Nematologia Brasileira, Piracicaba, v. 33, p. 54-60, 2009.

PRABHU, A. S.; FILIPPI, M. C. C.; RIBEIRO, A. S. Doenças e seu controle. In: SANTOS, A. B.; STONE, L. F.; VIEIRA, N. R. A. (Ed.). A cultura do arroz no Brasil. Santo Antônio de Goiás: Embrapa/CNPAF, p. 561-590, 2006.

RODRIGUES, A. A.; FORZANI, M. V.; SOARES, R. D. S.; SIBOV, S. T.; VIEIRA, J. D. G. Isolation and selection of plant growth-promoting bacteria associated with sugarcane. Pesquisa Agropecuária Tropical, Goiânia, v. 46, n. 2, p. 149-158, 2016.

RYU, E. On the Gram-differentiation of bacteria by the simplest method. Journal of the Japanese Society for Veterinary Science, Japan, v. 7, p. 31, 1938.

SANTOS, G. R.; CHAGAS, J. F. R.; TAVARES, A. T.; CASTRO NETO, M. D.; SARMENTO, R. A.; CHAGAS JÚNIOR, A. F.; NASCIMENTO, I. R. Danos causados por doenças fúngicas no arroz cultivado em várzeas no Sul do Estado do Tocantins. Bragantia, Campinas, v. 70, n. 4, p. 869-875, 2011.

SOSBAI - SOCIEDADE SUL-BRASILEIRA DE ARROZ IRRIGADO. Arroz irrigado: recomendações técnicas da pesquisa para o Sul do Brasil. Cachoeirinha: Sociedade Sul-Brasileira de Arroz Irrigado, 2018. 205 p.

SOUZA, E. C.; VESSONI-PENNA, T. C.; OLIVEIRA, R. P. S. Biosurfactant enhanced hydrocarbon bioremediation. 
International Biodeterioration \& Biodegradation, Barking, v. 89, p. 88-94, 2014.

SOUZA JÚNIOR, I. T.; SCHAFER, J. T.; CORRÊA, B. O.; FUNCK, G. D.; MOURA, A. B. Expansion of the biocontrol spectrum of foliar diseases in rice with combinations of rhizobacteria. Revista Ciência Agronômica, Fortaleza, v. 48, n. 3, p. 513-522, 2017.
SUNDER, S.; SINGH, R.; AGARWAL, R. Brown spot of rice: an overview. Indian Phytopathology, New Delhi, v. 67, p. 201-215, 2014.

ZARPELON, T. G. Caracterização de rizobactérias e eficiência Rizolyptus $^{\circledR}$ no enraizamento e crescimento de eucalipto. 2007. 82 f. Dissertação (Mestrado em Fitopatologia) - Universidade Federal de Viçosa, Viçosa, 2007. 